\title{
Games to Learn: An Update from 2010
}

\author{
Ali Alene Carr-Chellman \\ University of Idaho
}

\begin{abstract}
This paper represents an update on my thoughts about gaming for learning 8 years after my TED talk (see https://www.ted.com/talks/ali_carr_chellman_ gaming_to_re_engage_boys_in_learning) and after several longitudinal studies conducted (mostly with Dr. Jason Engerman). These ideas have evolved for me significantly, and this paper represents an opportunity to give an overview of what gaming to learn is, how we can, as a field, use games for learning, and update the basic understandings of games to learn, bringing research findings to bear on these foundations.
\end{abstract}

Keywords: Gaming; Gender; Disengaged learners

This paper represents an update on my thoughts about gaming for learning eight years after my TED talk and after several longitudinal studies, conducted mostly with Dr. Jason Engerman. These ideas have evolved significantly for me, and this paper represents an opportunity to give an overview of what gaming to learn is, how we can, as a field, use games for learning, and update the basic understandings of using games to learn, bringing research findings to bear on these foundations.

\section{Where I Started}

When I gave my TED talk in 2010, on 10/10/10 to be precise, I was a relative newcomer to the area of games education research. My focus was on games as a medium, a conduit through which an expression of boy culture (Tyre, 2009) could be effectively communicated (Carr-Chellman, 2012). As I pointed out in my TED talk, the purpose here is to help all active learners, though the majority tend to be boys, to better benefit from education. There are indeed plenty of girl gamers, though the kinds of games that girls play tend much more toward the social than the first-person shooter strategy game. The purpose of the original TED talk was to lay out the ways in which the culture of boys (active, competitive, technology-oriented, physical, assertive) tends to be in direct conflict with traditional school culture. I am not sure I completely understood this at the time of the TED talk, but my instincts were guiding me toward a focus on boys, and more broadly, toward active kids who are disengaged from their own learning (e.g., Rabone, 2013). 
In the TED talk, like most educational technologists, I started with a solution to the problem of disengaged boys. I began this work by doing a great deal of research and focused reading on the experience of boys in traditional classroom settings (Kindlon, Thompson, \& Barker, 2000; Noguera, 2003; Tyre, 2009). This work had led me to recognize that the potential for gaming offered a significant inroad for possible re-engagement with boys who had essentially disengaged from their early years of schooling (Prensky, 2006). All of this was as much a part of my own personal experience as it was based on my many years as a scholar in learning technologies. I had observed my own sons struggling with traditional classrooms. I had also observed them experiencing amazing learning opportunities in games -narrative rich, demanding, gorgeous games.

I was graciously ushered into the company of amazing researchers in gaming and learning. The UW Madison group, led by Drs. Squire \& Steinkuehler (Squire, K, 2008; Steinkeuhler \& King, 2009) regularly hosted a gaming conference with all the major leaders, and I was able to send some of our initial research out to that conference with my students. I felt much the impostor, having done most of my research in instructional design, userdesign, and system-wide school change. Of course, this background did prepare me for the road ahead, which involved deep understandings of culture, learning, curriculum, engagement, and the role of educational technologies.

In 2010, I made connections between boys' experiences in traditional classroom settings, and the potential for games to offer significant learning experiences. I was on the right track, but I found that my initial thoughts to encourage large gaming companies to create attractive, amazing learning games potentially even as a PR move, was the wrong direction. First, I idled a bit and learned how we might use games in classrooms in a relatively traditional way (MacKenty, 2006; McLester, 2005; Williamson, Land, Butler,\& Ndahi, 2004).

\section{Idling}

While we are waiting to get on the road here, one item worth exploring is the various ways that we have and can use games to learn. While my path takes us toward Commercial Off the Shelf (COTS) games, there are a wide variety of other ways to think about games in traditional classroom settings, including:

- Identifying games that your students are playing at home, and mapping them onto existing curriculum goals;

- Utilizing drill and practice games for rote memorization (I do not like this much as I feel that it continues a coercive learning model that tends to disengage rather than engage);

- Identifying strong educational narrative games to create project-based learning units around; 
- Asking the learners what they would like to try to learn via games;

- Designing new innovative video or educational games;

- Studying game mechanics;

- Utilizing non-technology-oriented games such as role plays, live action, cards, kinesthetic or board games that are linked to curricular outcomes;

- Using games as a reward for good behavior or strong academic achievement (again, this is not my favorite as it tends to externalize the locus of control);

- Focusing game use on the processes of failure or development of grit by studying, even collecting, data on the ways one learns to game;

- Utilizing books and other related websites that teach about gaming tricks and tactics to help teach literacy skills.

- The list could go on and on, but our engine is warmed up and ready to go, so let us continue on down the pathway that I was travelling as my understandings of gaming and disengaged learners deepened.

\section{Shifting into Second Gear}

Since my TED talk, I have had dozens of people approach me with the 'next best' learning game. They are earnest, thoughtful, intelligent designers with great ideas, and I do not want to dampen the potential for good and always better learning games. Some of them have been exceptionally promising and I have often tried to help in the development of a good tool or game. However, at some point between 2011 and 2012, I shifted gears away from trying to create the best possible learning game, a game that at its core is educational, to better understanding how COTS games can be used in traditional classroom settings. My initial thoughts had been that if we could make educational games as attractive as COTS games, with effective graphics, immersive narratives, and amazing musical scores, this would turn the tide among disengaged learners. Unfortunately, this was short-sighted. It neglected to fundamentally understand that better educational games would likely just further a coercive learning agenda (Kohl, 1995). Control breeds control. As Kohn points out,

Some who support coercive strategies assume that children will run wild if they are not controlled. However, the children for whom this is true typically turn out to be those accustomed to being controlled - those who are not trusted, given explanations, encouraged to think for themselves, helped to develop and internalize good values, and so on. Control breeds the need for more control, which is used to justify the use of control (1999, p. 33). 
Making that control prettier, or more engaging, is not the solution to the problems of disengaged learners.

It is possible that high-end educational games with strong narratives and graphics and musical scores would appeal to learners, particularly to those learners for whom traditional classroom activity has been dis-engaging. But would this be perhaps mostly because what they were experiencing in the traditional classroom is inordinately boring to them? So yes, gaming is better than a lecture (Boeker, Andel, Vach, \& Frankenschmidt, 2013); at least it is a two-way conversation, but is it as good as we can get? Is it something that we think can really arouse minds to engage them in significant learning?

I talked to some game designers, including some pretty big names, and asked them, why not try the public relations gains from creating truly excellent educational games? If I had not already pieced it together, their voices were clear. There is no need to create great educational games. Kids hate them (Smith, 2017). And this is true. I challenge any educational game designer who believes they have cracked the code to create the perfect educational game and put it on a table beside a major label, say Call of Duty or Fortnite, and ask a group of active learners, maybe boys, to come through a mall and look at those two games, side-by-side and decide which one they want to play for the next half hour. My bet is COD or Fortnite will beat the learning game hands down, and consistently across most groups. Is it just because they have a better musical score, a deeper narrative, a more beautiful graphical interface? Or is there something fundamental about the fact that a game is aimed at specific learning goals that handicaps it from being truly interesting to disengaged learners? Is it, as Kohn (1993) and Kohl (1995) have pointed out, about a resistance to being controlled, told what to learn? Does that in and of itself render educational games ineffectual?

This realization brought me to a place where I was not entirely sure what the next step was going to be. If the solution was not making the best educational game the world had ever seen, then what was it? I saw the power of games, so I knew that was a part of the equation. What I did not realize was that I needed to turn the equation on its head.

\section{Third Gear}

Once I managed to get my head straight about what games we were really focused on (COTS, not educational games), I did some informal observations among my kids and their friends as they played games together. I realized from them, from their talk and from their activity, that they were learning a great deal in the process of video gaming (CarrChellman, 2012). I started to ask them about whether this observation was also their lived experience. Indeed, they confirmed that, "Yeah, I go to school for six hours, but when I come home, that's when I get to learn new stuff," which was uttered by my 10 -year-old prior to his years at a project-based school where he was far more engaged. I realized that it was overwhelmingly true; they were learning so much from gaming, but was it (a) translatable into the traditional classroom achievements necessary for advancement, and/or (b) aligned with what was being taught in the traditional classroom in any way(s)? 
The first part of that question is difficult to answer. There are a few small bits of data or published evidence that might compel us to think that this assertion has some merit (Eames, 2014; Thomas, 2017). Businesses are now hiring off of leaderboards, even without degrees (Marr, 2016), there are significant college scholarships available for arena video gamers (Kostier, 2018; Thomas, 2018), and as a gaming pro (sort of like a golf pro), you can play against wealthy gamers to see if they can beat a leading gamer at a particular title (Savov, 2014; Utting, 2014). So, in traditional terms, there are some small glimmers of achievement and advancement. However, in the larger more general sense, it is nearly impossible to know this. I had proposed a few possible studies that might look at things like gaming and social class mobility, though they would merely offer correlations, not a true sense of causality which would more determinedly answer the question of whether gaming impacts achievement directly or indirectly.

The second part of the question is a bit more straightforward, and Dr. Jason Engerman, along with a team of graduate students at Penn State during my time there, spent several years looking at this question through longitudinal studies of middle school, high school, and college boys who game. These studies sought ways to directly map learner experiences in gaming to traditional academic outcomes. Fortunately, we found some significant themes and trends based on self-report interviews and observations, particularly around 21st Century Learning outcomes and literacy learning outcomes. Two broad areas of positive outcomes are grit development and literacies (Engerman \& Carr-Chellman, 2014; Engerman, MacAllan, \& Carr-Chellman, 2018; Yan et al., 2017).

While not all learning in gaming was easily mapped directly onto common core competencies, many skills were, including; teamwork, followership/leadership, inthe-moment communications, use of technology for communications, clarity in communications, problem solving, strategic thinking, and critical thinking. We also found evidence of several literacy skills including cultural literacy, operational literacy, digital literacy, and critical and morphing literacies in our findings. While it is difficult to discern when asking a boy "What do you learn when you game?", understanding their learning is more transparent once you begin to ask, "What do you do when you game?" From these interviews, we gained insight into how boys who game see failure in school (bad, hurtful) versus failure in gaming (good, growth), how they see themselves as learners, and their own metacognitive processes. These findings were compelling in terms of supporting the notion that, for some boys, learning experiences were more powerful in non-formal (in this case gaming, but it could also be scouting or sports) settings than in formal (traditional school) settings.

During this part of my development in the inquiry around gaming and learning, I began two other projects that helped to formulate my overall perspective on gaming and learning. First, I designed a course and started teaching in-service teachers about the potential of gaming. Second, I began speaking about these new ideas and research findings to groups of teachers, principals, superintendents, parents, community members, school board leaders, and school community leaders. These activities led to a very different 
understanding of the obstacles associated with gaming in learning. They also led to some new insights around boy culture and why gaming is so central to that culture.

Unlike most courses on gaming and learning that are available online in educational technology programs, the course I designed focused teachers on COTS games as curricular material. Most such courses focus on either a survey of good educational game tools or the creation/design of new educational games aligned with specific learning goals. These are reasonable approaches, but mine was a bit unorthodox. This novel approach to advocating for COTS games led to an interesting response from in-service teachers, focused primarily on why it is impossible to use COTS games in classrooms, primarily owing to the violent nature of such games. This uncovered an interesting dynamic.

In most cases, teachers were reluctant to consider violent COTS games as curricular material because of the risks of rejection by parents, leaders, and policy makers. Many of them recognized the value of such games for re-engaging a group of disengaged active learners, but they feared the backlash they would be likely to face if they adopted them. The course called for teachers to build a curricular unit around a COTS game. Around $80 \%$ of learners tried to identify an educational rather than a COTS game, and when pressed, many of them tried to argue that since the game was on Steam, or since it was a popular game, it qualified as a COTS game. However, the prompt within the course was to "identify a COTS game that your students currently play" and utilize it to build a unit with a single focused learning goal. In education, there is a strong advocacy to "take your students where they are", meaning working with students from within their own experiences, strengths, and frame. When asked whether teachers took their learners from where they were, generally teachers agreed they had not, but that they were concerned that doing so would create problems. I use this illustration not to denigrate the good decision making that teachers employed in this kind of case, but to illustrate how difficult it is to overcome a traditional trajectory that has left certain cultures behind.

Why was I so insistent that we use COTS games in the course versus traditional educational games? As I mentioned earlier, I have become thoroughly convinced by influential game designers that educational games are universally discounted by learners as only slightly interesting when compared with dry presentation of traditional material in a traditional classroom. So, using COTS games made sense, despite the likely negative valence of violence in classrooms. Despite this, it is more than this surface reasoning, as I have come to understand that the intractable problem of schooling and school change is deeply rooted in the culture of classrooms, which Sarason (1996) realized so long ago. Indeed, our classrooms and schools are fundamentally places that honor some cultures and not others. Traditional instruction is founded on an assumption that adults, teachers, principals, and parents know what is essential for youth to learn. This assumption bleeds over into an assumption that staying inside the lines is essential. As accountability has ratcheted up, so has the rejection of play, roughhousing, violent fantasy drama, and competitive sports (Entin, 2011; Vivian, 2009). 
The second part of this journey was a series of speaking engagements to a wide variety of K-12 stakeholders. As a result of the TED talk and subsequent research publications, I had the honor and pleasure of speaking about gaming to learn all over the US and beyond. These audiences ranged from librarians to teachers, from parents to politicians, and from school boards to community leaders. Here again, I heard echoed the same concerns that the in-service teachers had expressed in my course: the violent nature of COTS games. I was asked repeatedly, "Can't we get the same thing but using games that aren't violent?" I quickly found myself answering that question in the negative, but I did not understand why at first. What was it about violent games that made them so much more fruitful for engaging dis-engaged kids? And boys in particular?

I found my answers in a text, Misreading Masculinity, by Newkirk (2002), which helped me understand why fantasy violent play was so critical to boy culture, and why it need not be feared. I delved deeper into the reports on mass media about the dangers of violent media's effects on youth and discovered how little real research was available on this topic (Adams, 2010; Zendle, Cairns, \& Kudenko, 2018). I began to see that what had happened here was a wholesale rejection of a critical part of boy culture. Related to my primary concerns expressed in the TED talk, in which I point out the concerns around zero tolerance policies, another way of rejecting violent boy culture, I realized that COTS games were a direct antidote to the rejection of boy culture in traditional schools. Admittedly, gaming is only one possible antidote; there are many other possible ways to address this problem, but it was becoming clear to me that what we needed to do, fundamentally, was to respect the culture of the disengaged learner.

\section{Overdrive}

So, now you have arrived with me on this journey to where I am today. From the TED talk eight years ago to today, there has been quite a lot of water under the bridge and a great deal of work that has been done to inform my thinking on the topic of gaming to learn. Having begun with the idea that gaming needed to have better bells and whistles, graphics, soundtracks, and narratives, I progressed to a place where I understood that the fundamental issues were not about the superficialities of the games (COTS versus educational) themselves, but they were rather about what it was that captured the interests of disengaged learners. Through a better understanding of the perceptions of disengaged learners when they game, I approached inquiry through the lens of 'what is learned when gaming?' The data associated with this line of inquiry led to a deeper understanding of the need for cultural sensitivity for disengaged learners and a respect for the culture of those who have been turned off by school for many years.

Where do we go from here? Now comes the difficult part. Having established that reengaging disengaged learners is primarily a cultural problem, that games are a cultural statement, and that games tend to be eschewed in schools because of violence, misunderstood media reports, and fear of reactions from community members, we now face the difficult process of systemic cultural change. This process is one which requires 
extensive study of the current situation, as each school, and the dedication to follow a process, such as the one outlined by Reigeluth, Jenlink, Carr and Nelson (1996), will be different.

While this is difficult, and not for the weak of heart, it is also among the most rewarding things one can do to focus on the systemic change needs of a community of learners and make their visions come true in real world-settings. I am hopeful that many of you reading this will consider, as you look at classrooms filled with learners who will report to their parents that "nothing interesting happened at school today", that disengagement is the most egregious waste of human potential in society today. If disengagement is a waste, it is just possible that gaming, alongside cultural system-wide change, could be an antidote. What kinds of systemic changes may be needed in combination with gaming to re-engage disengaged, active learners, boys and girls? The active, competitive, assertive, physical, technology-centric learner (boy or girl) is at a decided disadvantage in today's school culture. Implementing COTS as a learning material can bring many of these facets of the disengaged learner into acceptance, particularly as COTS game experiences are seen as "legitimate" and powerful skill building learning events. Thus, alongside dramatic system-wide reconceptualization of engaged learning, continuing the process of mapping learning and 21 st century skills onto gaming as a curricular material remains among the most promising pathways toward re-engaging the disengaged learner. 


\section{References}

Adams, J. U. (2010). Effects of violent video games. Los Angeles Times. May 3, 2010. Retrieved from: http://www.latimes.com/health/la-he-closer-20100503-story. html

Boeker, M., Andel, P., Vach, W., \& Frankenschmidt, A. (2013). Game-based e-learning is more effective than a conventional instructional method: $A$ randomized controlled trial with third-year medical students. PLoS One 8,(12).

Carr-Chellman, A. A. (2012). Bring Back the Boys, Learning \& Leading with Technology, $39(7), 12-15$.

Eames, J. (2014). What game-based learning can do for student achievement. Retrieved from https://www.edsurge.com/news/2014-05-28-what-game-basedlearning-can-do-for-student-achievement

Engerman, J. A., \& Carr-Chellman, A. (2014). Boys and video games: What learning occurs from video game play and how might it map to the common core standards? In Spector, M. (Ed.) Proceedings of the Association for Educational Communication and Technology on Research, Theory and Development. (pp. 280-287). Jacksonville, FL: Association of Educational Communications and Technology.

Engerman, J. A., MacAllan, M., \& Carr-Chellman, A. A. (2018). Games for boys: A qualitative study of experiences with commercial off the shelf gaming. Educational Technology Research and Development, 66(2), 313-339.

Entin, E. (2011). All work and no play: Why your kids are more anxious, depressed. Retrieved from https://www.theatlantic.com/health/archive/2011/10/all-workand-no-play-why-your-kids-are-more-anxious-depressed/246422/

Jenlink, P. M., Reigeluth, C. M., Carr, A. A., \& Nelson, L. M. (1996). An expedition for change: Facilitating the systemic change process in school districts. Tech Trends, 41(1), 21-30.

Kindlon, D. J., Thompson, M., \& Barker, T. (2000). Raising Cain: Protecting the emotional life of boys. New York: Ballantine Books.

Kohn, A. (1999). Punished by rewards: The trouble with gold stars, incentive plans, $A$ 's, praise, and other bribes. Boston, MA, US: Houghton, Mifflin and Company.

Kohl, H. R. (1995). "I won't learn from you": And other thoughts on creative maladjustment. New York: New Press, Distributed by Perseus Distribution. 
Kostier, J. (2018). Esports: The new football scholarship? Gaming scholarship for college grew $480 \%$ last year. Retrieved from https://www.forbes.com/sites/ johnkoetsier/2018/05/12/

MacKenty, B. (2006). All play and no work. School Library Journal, 52, 46-48.

Marr, B. (2016). Can you find your next job by playing video games? Retrieved from https://www.linkedin.com/pulse/

Newkirk, T. (2002). Misreading masculinity: Boys, literacy, and popular culture. Portsmouth, $\mathrm{NH}$ : Heinemann.

Noguera, P. A. (2003). The trouble with Black boys: The role and influence of environmental and cultural factors on the academic performance of African American males. Urban Education, 38(4), 431-459.

McLester, S. (2005). Game Plan. Technology and Learning, 26(3),18-26.

Prensky, M. (2006). "Don't bother me Mom, I'm learning!": How computer and video games are preparing your kids for twenty-first century success and how you can help!. St. Paul, Minn: Paragon House.

Rabone, D. (2013). How game mechanics can revitalize education. Retrieved from https://www.eschoolnews.com/2013/02/12/how-game-mechanics-canrevitalize-education/?ast $=1$ \&astc $=10454$

Sarason, S. B. (1996). Revisiting "The culture of the school and the problem of change". New York: Teachers College Press.

Savov, V. (2014). Inside the life of a pro gamer: E-sports are turning silly teenagers into disciplined professionals. Retrieved from https://www.theverge. com/2014/7/21/5919973/inside-the-life-of-a-pro-gamer

Smith, E. (2017). Educational video games just never got things right. Retrieved from https://motherboard.vice.com/en_us/article/78y4g9/educational-video-gamesjust-never-got-things-right

Squire, K. (2008). Video games and education: Designing learning systems for an interactive age. Educational Technology, 46(2), 17-26.

Steinkuehler, C., \& King, B. (2009). Digital literacies for the disengaged: Creating after school contexts to support boys' game-based literacy skills. On the Horizon, 17(1), 47-59.

Thomas, A. (2017). These 3 game-based components can increase student achievement-here's how. Retrieved from https://www.eschoolnews. com/2017/10/09/game-based-learning-achievement/ 
Thomas, D. (2018). Here's how to get a full-ride scholarship for playing video games. Retrieved from https://news.vice.com/en_us/article/mbkeg3/heres-how-to-geta-full-ride-scholarship-for-playing-videogames

Tyre, P (2008). The trouble with boys: A surprising report card on our sons, their problems at school, and what parents and educators must do. New York: Crown Publishers.

Utting, C. (2014). The top 8 richest professional video game players in the world. Retrieved from https://wegotthiscovered.com/gaming/top-7-richest-progamers-world/

Vivan, C. (2009). Three strikes and you're out: Reasons to eliminate sports from schools. Journal of Inquiry \& Action in Education, 2(2), 278-187.

Williamson, K. M., Land, L., Butler. B., \& Ndahi, H. B. (2004). A structured framework for using games to teach mathematics and science in $\mathrm{K}-12$ classrooms. The Technology Teacher, 64, 15-18.

Yan, S., Mun, Y., Engerman, J. Moore, J. L. (2017). Boys and video game play: Reengaging boys in the classroom. Culture, Learning, and Technology, 165-179.

Zendle, D., Cairns, P., \& Kudenko, D. (2018) No priming in video games. Computers in Human Behavior, 78, 113-125. 